\title{
Some Thoughts on Preferred Qualifications in the Search for Academic Jobs
}

\author{
Freddy A. Paniagua \\ University of Texas Medical Branch, Galveston, USA \\ Email: faguapan@aol.com
}

How to cite this paper: Paniagua, F.A. (2019) Some Thoughts on Preferred Qualifications in the Search for Academic Jobs. Open Journal of Social Sciences, 7, 261-268. https://doi.org/10.4236/jss.2019.710021

Received: September 24, 2019

Accepted: October 19, 2019

Published: October 22, 2019

Copyright $\odot 2019$ by author(s) and Scientific Research Publishing Inc. This work is licensed under the Creative Commons Attribution International License (CC BY 4.0).

http://creativecommons.org/licenses/by/4.0/

\begin{abstract}
In an effort to examine the fairness of academic job postings, advertisement sources (e.g., APA Monitor on Psychology, Higher Education Jobs, Indeed, the Chronicle of Higher Education) for academic positions (e.g., assistant professor, chairs, deans, presidents) were reviewed to identify examples of the "required" and "preferred" qualifications associated with particular academic positions. "Required" qualifications are generally defined as being inherent to the performance of the job (e.g., a doctoral degree) and are under the control of the applicant. This article argues that "preferred" qualifications are under the control of the institution advertising the academic position and that, in some cases, they should not be emphasized because they are unnecessary, unconnected to the environmental context or to the nature of the job, discriminatory, and invented. In addition, there are also scenarios where a given preferred qualification would be critical to performing the job, and would in fact be a required qualification for that job. This article describes these types of qualifications in more detail and provides real world examples of their use in academic job listings.
\end{abstract}

\section{Keywords}

Academic Positions, Preferred Qualifications, Faculty, Recruitment, Search Committee

\section{Introduction}

Advertisement sources (e.g., APA Monitor on Psychology, Higher Education Job, Indeed, the Chronicle of Higher Education) for academic positions (e.g., assistant professor, chairs, deans, presidents) were reviewed to identify examples of required (or basic) and preferred (or desired) qualifications associated with the particular academic position. The "required" qualifications are generally in- 
herent to the nature of the job and under the control of the applicant. Examples of these qualifications include having a doctoral degree, evidence of teaching and research activities, a record of publications in peer-reviewed journals, expertise with a particular technique (e.g., atomic and molecular spectroscopy), and having a license to practice in the state where the candidate is applying. In the case of these required qualifications, the search committees generally agree 100\% with the applicant's submission of materials to support their ability to fulfill such qualifications (e.g., reporting peer-reviewed articles in the curriculum vitae). The "preferred" qualifications, however, are under the control of the institution and, in some cases, they are not inherent to the nature of the job. As observed by Perlmuter [1], the underlying meaning of "preferred" qualifications is: "it would also be nice if you had these."

Academic institutions generally include guidelines that search committee members are expected to use when they use the terms "required" and "preferred" during the interview process. Such guidelines are developed in response to the principles of equal employment opportunity (EEO) as demanded by the US Equal Employment Opportunity Commission [2]. An example of such guidelines can be found in this link from the University of California, Riverside-UCR [3]. For example, in their guidelines UCR observes that having knowledge of applicable policies and procedures is a preferred qualification in this academic institution. The guidelines also provide examples of how the "required" qualification should be defined and assessed. For example, if the required or basic qualification is having a doctoral degree it would be incorrect to define it broadly as "a doctoral degree from an institution of higher education." The correct wording, in this case, would be more specific: "a doctoral degree in psychology with emphasis on the assessment, diagnosis, and treatment of mental disorders as they are described in the DSM-5" [4]. In addition, research committee members should be able to assess the particular required qualifications by reviewing the curriculum vitae of the applicant and the official transcripts summarizing the doctoral level courses the applicant took during his/her graduate training.

Although the terms "required" and "preferred" qualifications have been discussed in prior sources [1] [5], the emphasis has been on the definition of such terms rather than on a critique of the use of such terms during the recruitment process in academic settings. As noted earlier, "required" qualifications are under the control of the applicant and can be assessed by reviewing the curriculum vitae of the applicant. In the assessment of "required" qualifications, the applicant and members on the search committee always agree about the veracity of such qualifications (e.g., doctoral degree in the particular academic job advertised). The inclusion of "preferred" qualifications during the interview process, however, is not only out of the control of the applicant but the impact of such qualifications on the negative (rejection) or positive (acceptance) outcome of the interview depends on how members on the search committee interpret the function of such qualifications when they are applied to the particular applicant. 
Therefore, this paper focuses on the use of preferred qualifications when screening candidates; and argues that, in some cases, the preferred qualifications listed in job descriptions are unnecessary, unconnected to the environmental context or to the nature of the job, discriminatory, and invented.

\section{Unnecessary Preferred Qualifications}

Preferred qualifications we will look at first are those that seem unnecessary. These are the qualifications that make applicants wonder about their relevance or necessity for the performance of a given job. For example, "understanding the value of a dollar" was listed as a "preferred" qualification for the new president of a college. Any educated person seeking this position should be able to understand that a dollar is not a peso. Therefore, it appears unnecessary to include this "preferred" qualification among those expected to perform that job.

In another example, a "sense of humor" was listed among the preferred qualifications for the selection of an executive in an academic setting. This is not only an unnecessary preferred qualification but applicants who are not "humorists" by nature would also find it difficult to show to the search committee that they have "a sense of humor." Besides, a "sense of humor" is a learned behavior and some applicants may have problems displaying this behavior during a face-to-face interview. Furthermore, some search committee members might consider an applicant's "sense of humor" inappropriate in a context where the content of the conversation should be considered "very seriously." For example, several years ago I applied for a chair position in a department of psychology. During the interview, a member on the "panel of faculty" (all members of the department as a group asking questions to the candidate) asked what I would bring to the department if I were selected. I replied by distributing a cartoon displaying a person sitting on a chair with the front feet of an elephant on his back. This humoristic answer was not perceived by that panel of faculty as a "sense of humor." I had been encouraged to apply to that chair position by a very good friend, and he later told me that my "humoristic" response to that question was a factor leading to the rejection of my application.

\section{Unconnected Preferred Qualifications}

Some preferred qualifications are not only unnecessary to the position listed, but actually appear to be completely unconnected to the environmental context of the institution or the nature of the job. For example, what specific skills would be needed during the interview to show that one has the "ability to initiate changes" when many members of the institution are opposed to changes; "ability to interact with diverse populations" in an academic institution where $99 \%$ of the employees are White; that one has the "energy to lead the university to new levels of growth" when some tenured professors feel they are fine at their current level; and how does one use the ability to be "oriented toward finding one's voice and clarify one's thoughts" in an environment that does not reward a "voice" or "thoughts" departing from the core values of the institution? 


\section{Discriminatory Preferred Qualifications}

In addition, some preferred qualifications may not only be unnecessary or unconnected to the environmental context or nature of the job, but they could also be perceived as a case of discriminatory preferred qualifications during the interview process. In this context, the unique manner in which a given "preferred" qualification is formulated may place certain applicants at a disadvantage, whereas others may benefit. For example, internal applicants would not find it difficult to show that they have the "ability to effectively communicate the mission of the institution with local communities," an "understanding of an appreciation of the role and function of the institution," that they have a good "knowledge of applicable policies and procedures of the institution," and that they have a good understanding of "the temper of the college or university." Contrast this to the difficulty that outside (external) applicants would encounter addressing the same preferred qualifications. When these preferred qualifications are listed, the announcement always includes some type of disclaimer: "[name of the institution] is an Equal Opportunity/Affirmative Action Employer." In this context, however, affirmative action principles would not apply because when these "preferred" qualifications are emphasized the insider candidate would be in a position of preferential treatment in the interview process, relative to the outsider candidate unfamiliar with the institution.

"Interpersonal skills" and "communication skills" are among the most cited preferred qualifications during the recruitment of faculty, chairs of departments, deans, presidents, etc., in academic institutions. However, cultural and ethnic variables could prevent an applicant from effectively demonstrating these preferred qualifications during the face-to-face interview. For example, search committee members looking for "interpersonal skills" (also known as "people skills") would assess the applicant's ability to interact with other people in the working environment. Yet in the interview setting, cultural differences could arise that prevent the applicant from displaying these abilities. For example, many American Indian, Asian, and Hispanic applicants would appear to lack "interpersonal skills" because of the differences in the way they interact with people of their own culture as opposed to interacting with people outside of their cultures, as would likely be the case during the interview. The applicant's ability to maintain "eye contact" during the interview is another key interpersonal skill the interviewer would carefully consider, but this could be misinterpreted in a cultural context. American Indian, Asian, and Hispanic applicants, for example, would avoid eye contact during the face-to-face interview not because they lack this particular interpersonal skill, but because they believe that lack of eye contact is a sign of respect toward the interviewer [6] [7].

"Communication skills" generally involve the applicant's ability to speak and write using the language required in the particular job, but this is rarely qualified in postings. In many instances, the announcement simply states that these "communication skills" should be "effective," "excellent," "highly developed," or 
"strong," without specifying how these qualities might be demonstrated. Putting aside the difficulty that applicants from any racial or ethnic background would encounter in their attempts to respond to these qualifiers (e.g., to show that such skills are "highly developed"), another major difficulty is the language barriers that may exist among applicants for whom English is not their first language. Hispanics or Asians, for example, might be quite eloquent in their primary language but have difficulty expressing themselves in English. Difficulties could arise even for some African Americans if they were to combine African-American Vernacular English (AAVE) with the standard English during the interview [8]. Members of the search committee would not spend their valuable time trying to understand what these candidates were saying (or writing) and would instead elect to reject them out-of-hand, despite the fact that such candidates might meet all "required" qualifications directly associated with the academic position (e.g., a doctoral degree in physics, perhaps among the 10 leading scientists in a particular area so complex that even some members of the search committee would have problems understanding).

\section{Invented Preferred Qualifications}

So we have demonstrated that "preferred qualifications" in academic job postings may be unnecessary to the performance of the job, unconnected to the institutional environment, and even discriminatory against culturally diverse (e.g., Hispanics) and outside candidates. There is a final category of "preferred qualifications": those that appear to be just invented or created in a hurry (without having been given careful thought) by those who write the particular job announcement. For example, achieving a "successful interview" was listed among the preferred qualifications for three full-time, tenure-track assistant professor positions. To get the job the interview must be, of course, "successful." But an interview that is "successful" in the mind of the search committee may lead to the rejection of the applicant (by the same committee!). This explains why applicants receive, for example, those letters stating that "many excellent applicants responded to our assistant professor position and all did very well during the interview process [i.e., a 'successful interview'], but sadly only one position was available and we are sorry you were not selected. Thank you for your interest in our institution. Please consider us in your future job search."

\section{Is the Distinction between Required and Preferred Qualifications Necessary?}

Regarding the good intentions of academic institutions in making sure that the applicant would fulfill not only the "required" qualifications but also those that are "preferred," the question is: Why would some institutions make that distinction when they know that many applicants may not be able to deliver what the search committee prefers? For example, the applicant's ability to "understand the temper of the college" was listed as a "preferred" qualification for the presi- 
dent of a community college. External applicants would not be able to show that they can understand that particular "temper." It would take months and even years to really understand the "temper" of any academic institution; but the external applicant would have to show on day one of the face-to-face job interview that he or she is ready to understand that particular "temper." Therefore, one would assume that an emphasis on that qualifier (i.e., temper) in the job announcement is a way to disqualify applicants before they even come for the job interview. The best guess under these circumstances is that the listing of "preferred" qualifications could be the underlying mechanism in the interview process that assures the rejection of applicants either during a preliminary review of the application or during the actual face-to-face interview. If true, the conclusion would be that the distinction between "required" and "preferred" qualifications is not necessary.

\section{A Modest Solution}

To make the application review and interview process fair, only those qualifications that are actually required to perform the job should be listed in job postings for faculty and executive positions. In addition, the search committee should make efforts to include only qualifications that could reasonably be addressed by all individuals applying to the same faculty and/or executive position.

Qualifications which appear to be so unique that only a small number of applicants would be able to address them should not be included among the skills listed. For example, "understanding the temper" of the college or university is a problematic skill to list as it cannot be generally applied to all applicants, particularly external applicants. Furthermore, if specific "preferred" qualifications are indeed necessary to perform the job, this point should be clearly stated. For example, fluency in Spanish would be not only a "required" skill but it could also be listed as a "preferred" qualification in those cases when the position involves the provision of mental health services to Spanish-speaking clients in settings specifically designed to assist Hispanics in need of psychological services. Similarly, a preferred qualification in a position searching for a microbiologist might be the applicant's strong expertise in bioterrorism. Because not all microbiologists have this type of expertise, the academic institution would have to make clear in the job description that, in addition to meeting required qualifications (e.g., a doctoral degree in microbiology), expertise in bioterrorism is a preferred qualification expected from anyone applying to the particular job (including insider and external applicants). In this example, expertise in bioterrorism would be not only a "preferred" skill but it is also a "required" skill due to the nature of the job to be performed.

\section{Conclusions}

In academic institutions, the task of search committee members is to select the "best" applicant for the particular position that the institution needs to fill. In 
the fulfillment of that task, members on that committee are generally informed about the required and preferred qualifications that they should track during the face-to-face interview process. Members on a given search committee would not have problems assessing the veracity of required qualifications (e.g., teaching experience associated with the particular academic job).

In the case of preferred qualifications, however, search committee members in academic institutions may be asked to screen for qualifications that are potentially unnecessary, unconnected to the environmental context or to the nature of the job, discriminatory, or invented. In this context, the ethical approach that members on such committees should take is to be sure that these negative dimensions (e.g., invented preferred qualifications) are excluded during the interview process. In general, the human-resources department (HR department) is the entity that develops guidelines for the identification of the required and preferred qualifications associated with a particular job. In the specific case of academic institutions, another ethical approach that members on search committees should apply is to inform the HR department in their institution about concerns they may have regarding some preferred qualifications and suggest that these qualifications should be removed from advertising a particular job when they can be demonstrated to be unnecessary for the performance of the job or perceived as "discriminatory" against both culturally diverse (e.g., African Americans, Hispanics, etc.) and external applicants.

\section{Author Biography}

Freddy A. Paniagua received his Ph.D. from the University of Kansas, and his postdoctoral degree from Johns Hopkins University School of Medicine. He is a retired, tenured professor from the Department of Psychiatry and Behavioral Sciences and currently adjunct professor, University of Texas Medical Branch (UTMB) at Galveston. He is Fellow with Life Status membership in the American Psychological Association (APA). He has authored over 50 peer-reviewed articles, six scholarly books, and two fiction books. He has also served on many search committees in academic settings.

\section{Acknowledgements}

I am grateful to Ms. Sheryl Holmberg, Vine House Creative

(http://www.vinehousecreative.com) for her insightful and constructive editorial suggestions, which significantly improved the content of this manuscript.

\section{Conflicts of Interest}

The author declares no conflicts of interest regarding the publication of this paper.

\section{References}

[1] Perlmuter, D.D. (2015) Career Lingo: 'Required' versus 'Preferred'. Chronicle Vitae. 
https://chroniclevitae.com/news/849-career-lingo-required-versus-preferred

[2] US Equal Employment Opportunity Commission. https://www.eeoc.gov

[3] University of California, Riverside (2014) Recruitment and Selection Strategies. https://intra.engr.ucr.edu/Intranet/Recruitment\%20And\%20Selection\%20Strategies \%20BCoE\%209-16-14.pdf

[4] American Psychiatric Association (2013) Diagnostic and Statistical Manual of Mental Disorders (DSM-5). American Psychiatric Association, Washington DC. https://doi.org/10.1176/appi.books.9780890425596

[5] Whitaker, M. (2019) How to Read a Faculty Job Ad. Chronicle of Higher Education. https://www.chronicle.com/article/How-to-Read-a-Faculty-Job-Ad/246921

[6] Paniagua, F.A. (2014) Assessing and Treating Culturally Diverse Clients: A Practical Guide. 4th Edition, Sage Publications, Inc., Thousand Oaks, CA. https://doi.org/10.4135/9781506335728

[7] Sue, D.W. and Sue, D. (2003) Counseling the Culturally Diverse: Theory and Practice. John Wiley \& Sons, New York.

[8] Smitherman, G. (1995) Black Talk. Houghton Mifflin, Boston. 